\title{
New Parks and Reserves in Nepal
}

\section{Melvin Bolton}

Four new national parks are being created in Nepal, three in the Himalayas, including Sagarmatha (Everest), to protect the mountain ecosystems with their wildlife and a fourth, the Royal Chitwan National Park (already gazetted) to protect the rich wildlife of the Terai. This park includes a now thriving population of great Indian rhino as well as tiger and gaur, and may be extended to include areas where both marsh crocodile and the highly endangered gharial are found. This ambitious new conservation programme was described by John Blower in Oryx, October 1973. Melvin Bolton is FAO Ecologist with the National Parks and Wildlife Conservation Project in Nepal.

Considerable progress has been made in setting up Nepal's four new national parks, three in the high Himalayas-Rara, Langtang and Sagarmatha (Everest) - and one, Chitwan, in the lowlands of the Terai, through the National Parks and Wildlife Conservation Project. This combined operation by HM Government of Nepal, the United Nations Development Programme (UNDP) and FAO has now been in operation for four years, and will continue for another two at the Government's request.

Three wildlife reserves also are located in the Terai-Sukla Phanta, Karnali, and Kosi Tappu - and one or more may be declared in the mountains, and hunting reserves will permit sport hunting on a controlled and scientifically managed basis. The Project also includes training of Nepalese wildlife biologists, both in Nepal and abroad, and the provision of technical expertise, field equipment and transport. WWF has assisted with vehicles and equipment.

Nepal does not 'teem with big game'; indeed the Nepal Himalayas are poorer in large mammals than the ranges to east and west. Thar Hemitragus jemlahicus and the two goat-antelopes, serow Capricornis sumatraensis and goral Nemorhaedus goral, are well distributed and quite frequently seen; blue sheep Pseudois nayaur, though much more local, are easy enough to observe where they occur, and troops of rhesus and langur monkeys are a familiar sight, the latter up to about 12,000 feet. Of the other large mountain mammals, however, one is lucky to catch even a glimpse without spending weeks on trek or embarking on a very determined search.

However, although tourism is important to Nepal's economy, the high mountain national parks have not been proposed primarily for their wildlife, nor solely for their superb scenery, rich flora or fascinating birdlife, but also because the ecological well-being of the mountains is essential to the welfare of mountain and lowland communities alike.

All life in the high ranges is part of a fragile and delicate ecosystem that is all too easily damaged and exceedingly slow to recover, and the consequences of destroying their vegetative cover can have the most profound effects in the lowlands, where flooding and silting affect vast areas of heavily settled and cultivated land. It is a sadly familiar story: deforestation and ero- 


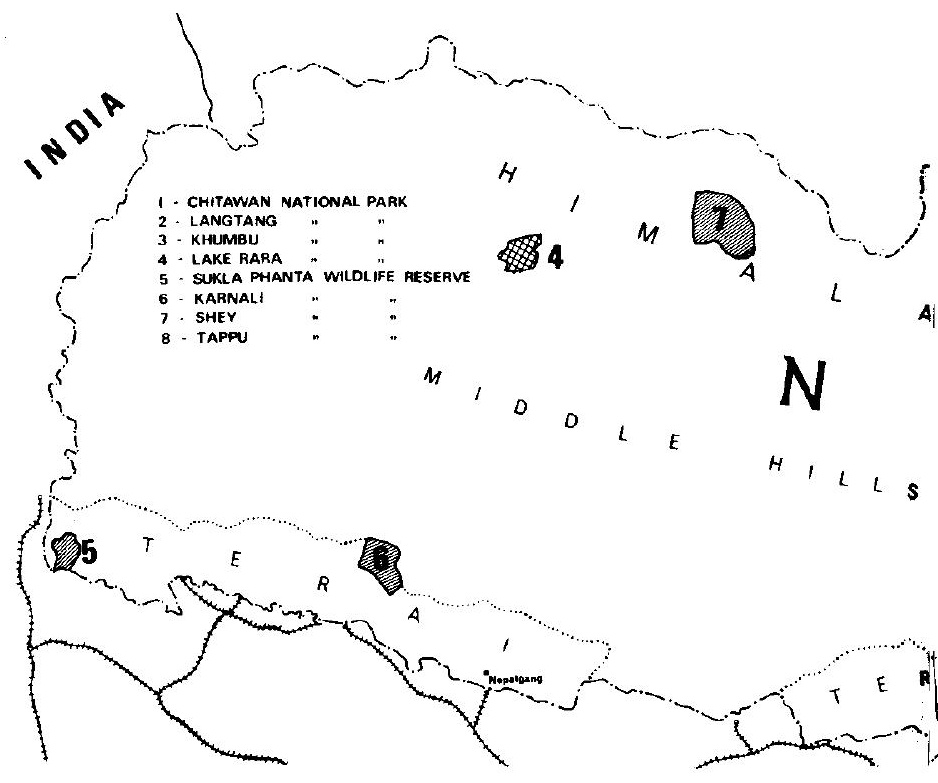

sion up-river affecting the water regime in areas far from the scene of destruction. And in Nepal the forces operate on an exceptionally grand scale.

The people living in these national parks will continue to do so, with the possible exception of Lake Rara, where resettlement may be feasible. The Sherpas in the Sagarmatha (Everest) region - and other ethnic groups in Langtang - will continue their traditional ways of life, cultivating the lower valleys and grazing stock seasonally up to the pasture limit. As elsewhere in the world, expanding populations and new developments have had a destructive impact: an upsurge in tourist trekking in the Nepal Himalayas has increased the demand for wood fuel and other facilities that cannot be met because of the slow rate of tree growth in these mountain areas. At 13,000 ft, for example, trees of only eight or nine inches diameter have taken 80-90 years to grow.

The mountain parks must demonstrate a more harmonious pattern of land use by both residents and visitors. Because of this they do not conform to the strict definition of national parks (although by zonation they will meet the criteria of the UN list of National Parks), but in the conservation of montane ecosystems they have a role. In the short term, in over a thousand square miles of the Himalayas, conservation practices will be increasingly employed, and research on management problems should produce conservation principles that can be applied elsewhere. There will have to be legal restrictions within the parks, but hopefully much will be achieved by voluntary cooperation and planned zonation of activities. It should be practicable to write into the management plans protection of the wildlife, natural vegetation and scenic beauty without bringing farmers and wildlife into conflict. Quarters for wardens and guards are being built in all three parks.

The national parks have been well chosen. Sagarmatha in the eastern Himalayas encloses an area of some 500 square miles around Mt Everest, extending from the upper limits of the pines at about $10,000 \mathrm{ft}$, through mixed broadleaved forest and oak and fir forests, then birch and rhododendrons to the alpine scrub and the permanent snows rising to the summit at $29,024 \mathrm{ft}$. 


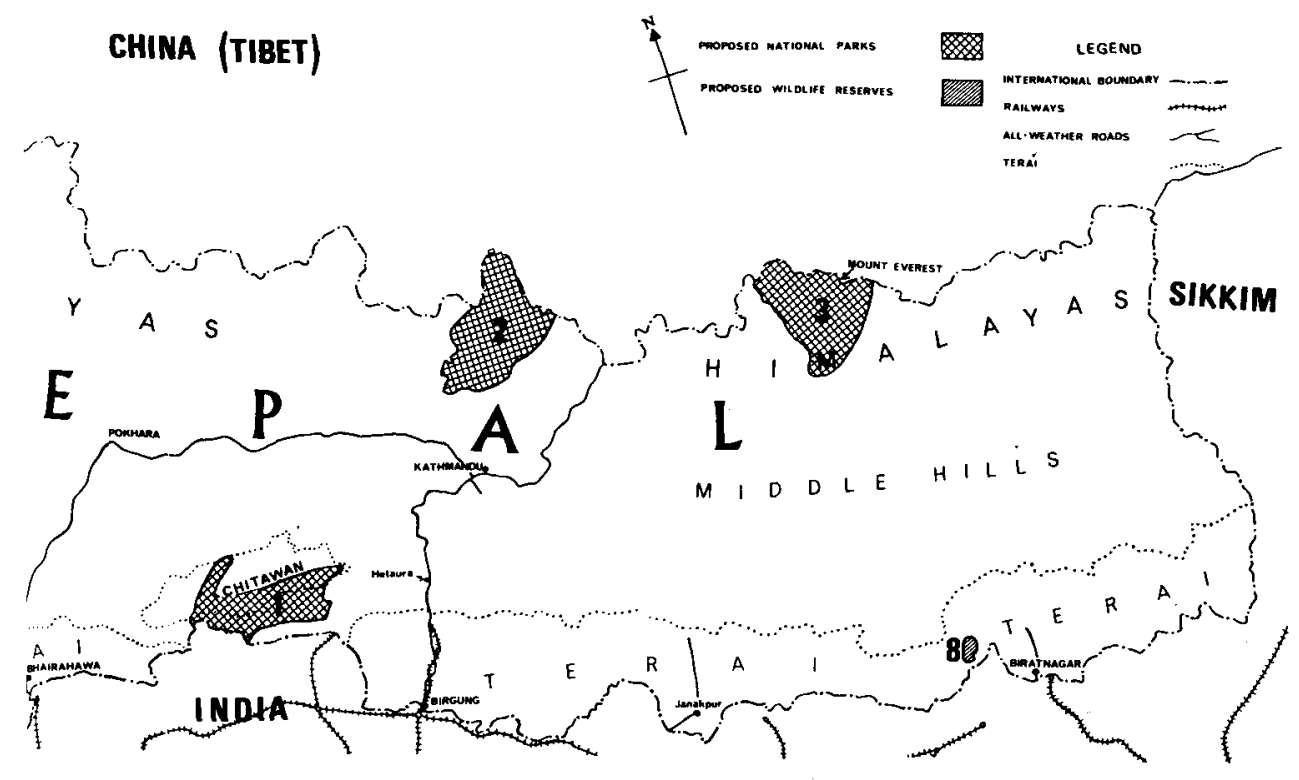

Langtang, which covers a similar area, to the north of Kathmandu, has a comparable altitudinal range from the lowest valleys at around $5000 \mathrm{ft}$ to the highest peak at $23,771 \mathrm{ft}$. Climate and vegetation, too, are similar, though Langtang, because it includes much lower valley lands, also contains patches of richly mixed temperate forest with many genera of trees and shrubs familiar to English gardeners. Both parks are increasingly popular with trekkers. Lake Rara National Park, covering 40 square miles, in the drier country of the west, includes Nepal's largest lake (four square miles) at an altitude of 10,000 feet. It also contains fine examples of the splendid mixed forests of the western Himalayas. Between them these three mountain parks will give protection to almost all the larger mammals of the Nepal Himalayas, including the threatened musk deer Moschus moschiferus and the red panda Ailurus fulgens. A notable exception is the blue sheep for which a separate reserve is to be established.

The fourth park, the Royal Chitwan National Park, which contains the greatest variety of wild animals to be found anywhere in Nepal, was established under the 1973 National Parks and Wildlife Protection Act, primarily to conserve the fauna and natural habitats of the Terai. To do this it must conform to the strict criteria of a national park, excluding all human settlements. Progress has been encouraging.

The park covers 210 square miles including part of the Siwalik range low but in places extremely rugged and broken hills forming part of the outer Himalayas - locally called the Churias and Someswars, and rising to about 2000 feet. Through the dry season the rivers flow gently as a series of shallow streams between broad sand and shingle beds, but a single monsoon may change their courses by hundreds of yards and sweep away acres of established forest land.

Sal forest covers 60 per cent of the park. It is usually called jungle, which gives most westerners a completely wrong impression, for most of it is no denser than an English beechwood. Well-grown sal trees Shorea robusta average about 80 feet and have a straight, greyish trunk and oval, leathery 
leaves. Forest dominated by sal, often stunted, covers the hills and extends onto the lower, flatter land where it reaches its maximum development before giving way to tall-grass flood plains and riverine forest associations. These are rich in birds - the park check list numbers over 250 species - and most of the park's twenty-odd species of large mammals also spend most of their time there. So, because the major rivers, the Narayani and its tributary the Rapti, form a large part of the park boundary, wildlife tends to be concentrated near the park's periphery.

A high priority in this park was to stop the poaching. The Nepalese park warden and an expatriate regional warden supported by FAO, devised a system of rewards to informers and patrols by park guards which proved so effective that only a single case of rhino poaching has been recorded in the last two years. Livestock encroachment is more difficult to eliminate because stock do sometimes genuinely stray accidentally and local people must not be needlessly antagonised - local support for the park is very important. Nevertheless, cattle pounds have been constructed and impounded stock is only released on payment of a fine. This has significantly reduced livestock encroachment, and the problem is now mainly confined to certain sections of the park periphery. Other problems include crop depredation by the wild animals and the less familiar one of local people cutting thatching grass within the park. Grass cutting is permitted during one month in each year, a concession that is clearly open to abuse and will require the utmost vigilance by the park's force of 130 military guards if the annual invasion for this cutting is not to get out of hand.

The national park guards, who are armed military men, now operate from well constructed and well sited outposts so that the park can easily be covered by foot patrols. There are good, motorable roads, but away from these the only practicable means of transport is elephant back, and in the broken country of the Someswars even elephants are of limited use. But the park would scarcely function without them. Only elephants can carry loads from one end of the park to the other during the monsoon months, July to October, when rivers are swollen, bridges submerged and the long-grass flood-plains are a quagmire. And for several months after the rains, until December or January, the rivers may still be too high for a vehicle to ford and the tall grass may not have dried enough to be burned off. In this unmotorable, and, for pedestrians, uncomfortable, dangerous country, visitors to Tiger Tops, the tourist lodge operated by concessionnaires within the park, are taken on elephant back, which in any case is more satisfactory for seeing the cover-loving wildlife of Chitwan. The best way to see the animals is to wait quietly in a tree hide or machaan by a waterhole, salt lick or river bank - but this requires time and patience.

In time the big mammals of Chitwan are likely to become easier to see as their numbers increase and they lose some of their fear of man; already there are signs that this is happening. Gaur Bos gaurus are extremely shy and normally remain in dense cover by the many water courses which dissect the forested hills, but recently they have been sighted several times in the foothills and occasionally in the early evenings down on the flood plains. The great one-horned rhinoceros Rhinoceros unicornis could hardly be called shy but only a few years ago it was in constant danger from poachers, its numbers drastically reduced and still dwindling. Today, following a three-year period 


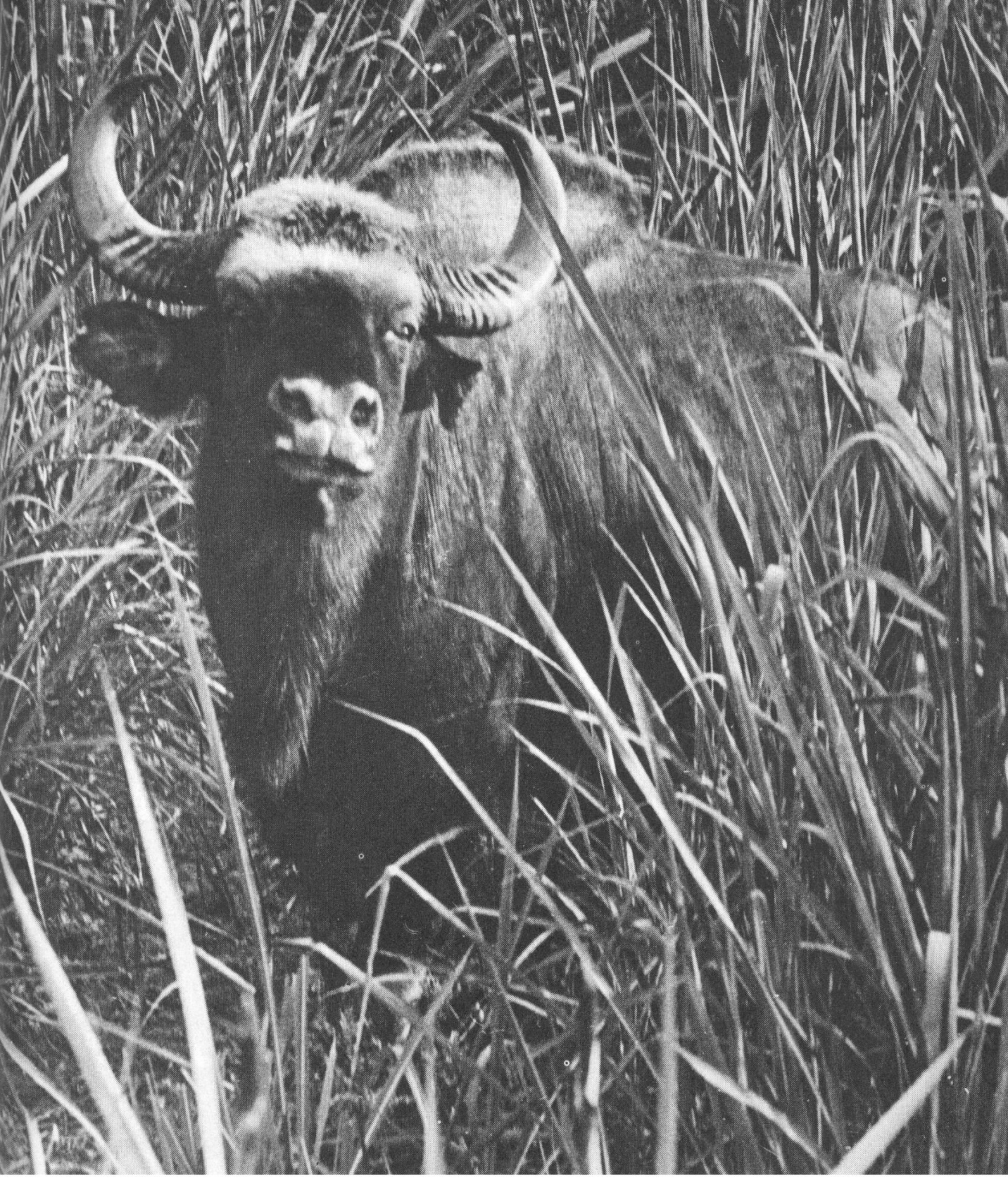

BULL GAUR in Chitwan National Park C. McDougal courtesy of Tiger Tops

of intensive observation and research by Andrew Laurie, a Cambridge zoologist supported by the New York Zoological Society, we have detailed information about its habitats and requirements and we know that the population of 250-300 individuals (all in and around Chitwan) is thriving. They are now one of the easiest animals to see in the park.

Spotted deer or chital Axis axis, probably the most commonly seen big 
mammal, usually move in small herds or family groups, but at times they come together in much bigger assemblies. Three other deer species are plentiful though far less gregarious: sambar Cervus unicolor, which extend from the flood plain to the tops of the highest ridges; barking deer Muntiacus muntjak, also fairly widespread, and hog deer Axis porcinus, which tend to remain in the dense cover of the flood plains where they are locally abundant, as are wild boar Sus scrofa. Sloth bears Melursus ursinus, though never abundant, are not scarce; they present the greatest hazard to those who must enter the long grass on foot, for they seem to have poor sight and hearing and can literally be stumbled upon; females with cubs will attack, clawing, even without such provocation.

Tigers are the subject of a full-time research project sponsored by the Smithsonian Institution and conducted by a team of Nepalese and American workers. Five wild tigers have been fitted with radio transmitter collars and valuable data on their movements and habits are being collected. Current 'guesstimates' of tiger numbers are around 25-30 within the park, although, of course, their home ranges, as with other predators, frequently extend outside the park; there are good numbers of tiger in the rugged and remote country immediately to the east and west.

The Nepal Government is now giving serious consideration to extending the park both eastwards and westwards, which would bring in more tiger, gaur and leopard besides the more plentiful deer and other animals, would shorten the present boundary with cultivated land, and would protect those rhino which presently spend much of their time outside the park. Moreover, another twenty miles of river bank would be brought under national parks

\section{CHITAL STAGS IN VELVET Melvin Bolton}

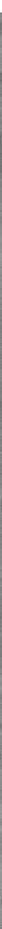


